\title{
Editorial
}

\section{UNIV. OF CONN.}

\section{The recent case of the baboon and the baby}

The recent case in which the circulation of a child with acute heart failure was connected temporarily to that of a baboon, in an attempt to save his life, attracted much public interest. It was implied that some new ethical principle was involved and it was even stated that the whole procedure was unnatural, monstrous and unethical. In fact, animal products, such as insulin, antisera and skin grafts, have been used widely and effectively for many years for therapy and prophylaxis, and most people accept their use without question. To join the circulation of a man to that of an animal is merely an extension of this principle, and many patients with acute liver failure have been treated temporarily in this way, some of them successfully. These procedures do not appear to have attracted much public attention and objections to the recent baboon incident would appear to be emotional rather than rational. We can see no ethical objection to it.

It would, however, be preferable for many reasons to use machines, rather than animals, to supplement or supplant the functions of organs when they fail. 'Heart-lung machines' are used for a few hours to provide extracorporeal circulation and respiration during operations on the heart, and 'artificial kidneys' are used, intermittently, for years in patients with irreversible renal failure. Despite intensive research, no effective machine has yet been devised to supplant the heart for the few days that are required in the sort of situation in which the baboon was used. On scientific grounds, most research workers see more hope in a mechanical approach than in a biological one, and there are good grounds to expect it to succeed within a few years. It might be argued that it was unethical to use in man a procedure which had not been tested thoroughly in experimental animals - an issue which does not seem to have been raised in the public debate. However, in this case the situation was desperate, there was a chance of success, and it is an axiom of scientific research that an idea cannot be proved wrong until it has been tested. The main debate, at present, should involve the scientific not the ethical issue.

\section{The abortion issue}

'Woman's right to choose' is a slogan now often seen on headings or on car stickers and in other public

\section{HEALTH CENTER LIBRARY}

places. In January 1975 both France and Austria passed legislation allowing abortion on demand for any woman during the first ro weeks of pregnancy. In Britain there is continuing debate about the 1967 Abortion Act, the Lane Committee's report and Mr White's Abortion (Amendment) Bill. Whatever may be the law of the land ethical problems relating to abortion will persist and extreme views are likely to be held for some time to come. A number of these are presented and discussed in the present number of the Journal and others will doubtless appear in the future. As in so many matters of ethics, there is no clear right or wrong and ultimate decisions must rest with individuals - indeed it could be said that if on any question there was only one answer that question ceases to be a matter of ethical debate. Even for one individual, let alone society, it is not easy to reach a conclusive attitude. Sir Dugald Baird, after a life time of daily consideration of individua 6 and national abortion problems, says in his article that he has 'gradually come round to the view thato abortion on request is the most realistic attitude ....? Others can be excused for still holding a more equivocal view one way or the other and in particular be commended for not trying to impose their own attitude on others.

What are the ethical issues? Few would deny that if a woman has a mole on her face she should have the right of choice as to whether or not it is removed. If a conceptus is regarded as a mass of cells like a mole then the same would apply. Mr Gardner takes a middle attitude between the fetus being a mass of cells or a person right from conception. His idea of a 'maternal-fetal unity' is a helpful one, as is his description of the differences between abortion and euthanasia. One can see the force of the argument that to consent to the extermination of a fetus is not far removed from euthanasia and the issue can hang on whether the conceptus is to be considered as a separate individual. In another connexion Bernard Levin has recently emphasized the danger to the progression of public thinking created even by quite a minor change of law in a particular direction. One step tends to lead to another.

Even if induced abortion is not regarded in the same light as the taking of life from a living or viable individual, ethical issues remain. The right to choose carries with it the burden of choice. As both Baird and Myerscough point out, we still lack objective evidence as to the affect of induced abortion, 
particularly in the young nullipara, on future fertility. It is true that therapeutic abortion is less likely to have an ill effect than 'back street abortion'. It is almost certainly true also that the earlier a pregnancy is terminated the less likely is the procedure to have any effect on subsequent childbearing. At the time of being given a choice a woman is likely to be in no state of mind to weigh up objectively all the pros and cons. Nor can she have full knowledge of the medical facts. To return to the mole analogy, certain moles carry serious risks if left alone and other risks if treated by certain methods. Is the doctor to warn the patient of ever conceivable complication and give her the statisticaln data? Is there such a thing as 'truly informed'? consent? Would not many women prefer that withiph liberal legislation the ultimate decision be made not be herself but by her doctor after full discussions? and consultations? If society, by legislation an public pressure, interferes with the doctor-patien? relationship the very basis of medical ethics will be eroded and it is for discussion whether the loss t\& the individual will not be far greater than the्छ apparent gain of free choice. 